Canadian Science Publishing

Canadian Journal of Earth Sciences Revue canadienne des sciences de la Terre

\title{
Comparing global and local calibration schemes from a differential split-sample test perspective
}

\begin{tabular}{|r|l|}
\hline Journal: & Canadian Journal of Earth Sciences \\
\hline Manuscript ID & cjes-2015-0015.R1 \\
\hline Manuscript Type: & Article \\
\hline Date Submitted by the Author: & 29-Jun-2015 \\
\hline Complete List of Authors: & $\begin{array}{l}\text { Gaborit, Étienne; Environment Canada, E-NPR } \\
\text { Ricard, Simon; CEHQ, } \\
\text { Lachance-Cloutier, Simon; CEHQ, } \\
\text { Anctil, Francois; Université Laval, Civil Engineering } \\
\text { Turcotte, Richard; CEHQ, }\end{array}$ \\
\hline Keyword: & $\begin{array}{l}\text { large-scale hydrologic modeling, local and global calibration, differential } \\
\text { split-sample test, model robustness, climate-change context }\end{array}$ \\
\hline &
\end{tabular}

SCHOLARONE ${ }^{m}$

Manuscripts 


\section{Comparing global and local calibration schemes from a differential split-sample test perspective}

É. Gaborit ${ }^{1}$, S. Ricard ${ }^{2}$, S. Lachance-Cloutier ${ }^{2}$, F. Anctil ${ }^{1}$, and R. Turcotte ${ }^{2}$.

1. Chaire de recherche EDS en prévisions et actions hydrologiques, Département de génie civil et de génie des eaux, Université Laval, 1065 Avenue de la Médecine, Québec, Qc, G1V 0A6, Canada.

2. Centre d'Expertise Hydrique du Québec (CEHQ), 675 boulevard René-Lévesque Est, Québec, Québec, Canada, G1R 5V7.

corresponding author: Etienne Gaborit, 6380 av. Boniface, Brossard J4Z3L7, 514-421-5305, 418572-2109, etienne.gaborit@ec.gc.ca 


\section{Abstract}

This work explores the performances of the hydrologic model Hydrotel applied to 36 catchments located in the Province of Québec, Canada. A local calibration (each catchment taken individually) and a global calibration (a single parameter set sought for all catchments) schemes are compared in a differential split-sample test perspective. Such a methodology is useful to gain insights on a model's skills under different climatic conditions, in view of its use for Climate-Change (CC) impact studies. The model was calibrated using both schemes on five non-continuous dry and cold years and then evaluated on five dissimilar humid and warm years. Results indicate that, as expected, local calibration leads to better performances than the global one. However, global calibration achieves satisfactory simulations while producing a better temporal robustness (i.e. model transposability to periods with different climatic conditions). Global calibration, in opposition to local calibration, thus imposes spatial consistency to the calibrated parameter values, while locally adjusted parameter sets can significantly vary from one catchment to another due to equifinality.. It is hence stated that a global calibration scheme represents a good trade-off between local performance, temporal robustness, and the spatial consistency of parameter values, which is for example of interest in the context of ungauged catchments' simulation, climate-change impact studies, or even simply large-scale modeling.

key words: large-scale hydrologic modeling, local and global calibration, differential split-sample test, model robustness, climate-change context. 


\section{1-Introduction}

For climate change (CC) impact studies, hydrologic models have to adequately represent physical processes under future conditions. In other words, they have to achieve satisfactory performances for periods with climatic conditions different from those used to train the model. However, it is generally common in Hydrology to assess model robustness (i.e. the model capacity to produce satisfactory simulations in validation) with using the conventional splitsample test - which consists in using calibration and test periods of similar (climatic) properties (Klemeš 1986). When it comes to CC applications, Xu (1999) and Seiller et al. (2012) recommend using a differential split-sample test (DSST, Klemeš 1986) which aims at evaluating the skills of a hydrologic model on a period with (climatic) conditions dissimilar from the calibration data.

Another important issue (among many others, see Xu et al. 2005) of CC impact studies pertains to the difficulty of implementing hydrologic models over very large areas. There are several possibilities to represent the detailed hydrologic behavior of a region. One could, for example, apply numerous versions of the same model and locally calibrate them at each gauging site (local calibration). But that leaves open the question of ungauged basins within that same region, and remains labor-intensive in the case where the large area is covered with a high number of streamgauges.

Distributed hydrologic models can partly overcome this problem, simulating flows at any point within the defined hydrographic network; this was explored for example by Pietroniro et al. (2007) over the Great Lakes. However, limitations associated with the lack of observed streamflows may remain an issue because the internal hydrologic simulation (i.e., the simulation 
at a point located upstream of the outlet) of a distributed hydrologic model is not always reliable (Andersen et al. 2001). Transferring parameters to ungauged catchments (which could be a solution to both aforementioned approaches' limitations) also remains hazardous (Xu et al. 2005, Gotzinger and Bárdossy 2007), mostly because of equifinality issues (Beven and Freer 2001, Bárdossy 2007). To overcome such limitations, a macroscale hydrologic model (Xu et al. 2005) may be locally calibrated using as many gauges as possible.

Another possibility would be to use a single physically-based distributed and calibrationfree hydrologic model over the whole area (see for example Mauser and Bach 2009). At large scales however, construction of such model is labor intensive and limited by data availability and quality (Pietroniro and Soulis 2001, Xu et al. 2005).

There is no easy solution to achieve a detailed representation of the hydrologic behaviors of a wide region. The Centre d'Expertise Hydrique du Québec opted for a lumped conceptual regionalization of the parameters of their operational model (Ricard et al., 2013). It follows the work of Fortier Filion (2011) and consists in identifying a unique parameter set for the semi-distributed hydrologic model Hydrotel (Fortin et al. 2001 a, b). This way, the hydrologic simulation still benefits from the many spatial heterogeneities of the southern portion of the Province of Québec, an area of $388000 \mathrm{~km}^{2}$. The spatial heterogeneities consist for example in the topography, soil types and land uses. Choosing a unique parameter set assumes that catchments with similar characteristics will express a similar hydrological behavior (Bárdossy 2007), and allows to preserve spatial consistency (the way parameters vary in space according to watershed properties) over the whole region. It is referred to as global calibration in Ricard et 
al. (2013) because the unique parameter set is obtained through a calibration process simultaneously taking into account the performance at all gauged stations inside the domain.

The aim of this work is to gain knowledge on the behavior, in terms of Hydrotel performances and robustness, of the local and global calibration schemes, when submitted to a DSST. This work is actually trying to answer two main questions: "does the Hydrologic model Hydrotel present enough robustness in the context of a DSST so that it can be applied with some confidence in CC impact studies?", and "does global calibration present some interest in terms of model performance and robustness so that it could reasonably be used to efficiently implement Hydrotel over very large watersheds?" The database available to the experiment consists of 36 gauged catchments, ranging from 200 to $15000 \mathrm{~km}^{2}$ with a mean area of 2735 $\mathrm{km}^{2}$ and a total area of $98460 \mathrm{~km}^{2}$, exempt of any major infrastructure that would modify their natural hydrologic regime (Figure 1). As previously stated, it is common practice to identify an optimal model parameter set for each of them (local calibration). This however leaves uncalibrated the rest (75\%) of the $388000 \mathrm{~km}^{2}$ territory targeted for a climate change impact study (Province of Québec, Canada - Figure 1). To circumvent this problem, it is proposed, following Ricard et al. (2013), to identify a global (unique) parameter set suitable to all 36 catchments (global calibration), which could be applied afterward to the other rivers of the area flowing into the St. Lawrence River. Because of the vastness of the territory, a semi-global calibration is also explored at the end, considering separately the western, eastern and northern sections of the global watershed (Figure 1) to independently perform a global calibration on each of these three main catchments. 
The manuscript is organized as follows: in section 2, the model, data base and study area are described. In section 3, the DSST framework used in this study is carefully explained, while sections 4 and 5 respectively present the results and conclusions emanating from this study.

\section{2-Model and data}

The territory in Figure 1 is drained by three large river systems: the Ottawa (west), the Saguenay (north), and the Saint Lawrence (east) rivers. The first two systems extend 144000 and $87000 \mathrm{~km}^{2}$, respectively, and lay on the low altitude orogenic system of the Canadian Shield (highest point reaching $1000 \mathrm{~m}$ ). The portion of the Saint Lawrence basin studied here $\left(157000 \mathrm{~km}^{2}\right)$, encompassing the land between the outlets of the Ottawa River and of the Saguenay River, is constrained to the south by the Appalachian Mountains, and is mainly composed of sedimentary material (limestone, sandstone). Urban and agricultural developments are mainly restricted to the Saint Lawrence valley.

Most of the 36 watersheds are exposed to the humid continental climate of the boreal forest, with variations driven by latitude and topography. The average total annual precipitation amounts to about $1000 \mathrm{~mm}$ with a substantial portion (about 25\%) falling in solid form, leading to a nivo-pluvial hydrologic regime dominated by a spring freshet (Dolores Bejarano et al. 2010). Yet the territory beyond the $50^{\text {th }}$ parallel is subjected to lower sub-arctic temperature and receives lesser precipitation totals.

Precipitation and temperature products provided by the Centre d'Expertise Hydrique du Québec (CEHQ) are available at a daily time step on a regular $0.1^{\circ}$ grid generated by the kriging 
of 971 meteorological time series extending from January 1, 1969 to December 31, 2010. Daily streamflows are available for the same period, but observations from December 1 to March 1 are not included in the calibration, because of ice effects that greatly diminish their reliability (CEHQ, personal communication).

The semi-distributed hydrologic model Hydrotel (Fortin et al. 2001a, b; Turcotte et al. 2003) was implemented following Ricard et al. (2013), leaving 13 free parameters for the simulation of the snowmelt, potential evapotranspiration, vertical water budget, and routing.

Hydrotel is a physically based, semi-distributed Hydrologic model (Fortin et al. 2001a, b; Turcotte et al. 2003). It simulates snow-related processes, evapo-transpiration, surface and subsurface runoff, vertical water budget, and streamflow routing. Since it does not take into account energy balance, Hydrotel's complexity can be considered as intermediary. It was implemented in this study following Ricard et al. (2013), i.e. by calibrating 13 free parameters.

\section{3-Differential Split-Sample Test methodology}

The general framework of the DSST methodology adopted here follows Seiller et al. (2012). Annual total precipitation $(\mathrm{P}, \mathrm{mm})$ and mean temperature $\left(\mathrm{T},{ }^{\circ} \mathrm{C}.\right)$ are exploited for the allocation of each hydrologic year into one of the four following climatic categories: Humid Cold (HC), Dry Cold (DC), Dry Warm (DW), and Humid Warm (HW). Precipitation and temperature are the most important inputs of a hydrologic model. Even if a classification based on annual values rests very crude, since the succession of the short-term dry and wet spells are aggregated into a single metric, one has to keep in mind that the objective of a DSST analysis is to provide insights on the robustness of the model to contrasted climate. Other statistical properties than (or in 
addition to) the annual total or average values could have been used to classify the different years' climates (such as their extremes, the number of days above or under a given threshold, etc.), but this was not performed here because such other statistics are more appropriate for studies focusing on specific flow aspects such as low or high values (Seiller et al. 2012), whereas we preferred placing this work under a more general framework.

A given year can then be located on a graph of the annual average temperature versus the total precipitation amount. One can next select the $x$ most extreme years in each of the four quadrants defined by Figure 2 below.

The DSST consists of two steps. The model is first calibrated on a set of selected hydrological years taken from the same climatic quadrant. Four calibrations under contrasted climate are hence available to the project, for each of the 36 watersheds (local) and for all the sites simultaneously (global). In a second step, the parameter sets are tested on contrasted climate: the model may be calibrated on $\mathrm{HC}(\mathrm{DC})$ and tested on DW (HW), which is here referred to as the diagonal 1 (diagonal 2) in Figure 2. Each of the two climatic diagonals can be used with the aforementioned direction (from cold to warm), or in the reverse direction (warm to cold). Note that non-continuous years are selected for the DSST, but simulation is conducted using a continuous period covering all selected calibration (or testing) years to avoid interruptions.

Other authors such as Vaze et al. (2010), Merz et al. (2011), or Coron et al. (2012), used sliding windows of several continuous years or decades to perform the calibrations and tests, instead of the strategy chosen here. However, using a small number of non-continuous years leads to higher climatic contrasts for the DSSTs than long continuous periods (Seiller et al. 2012). 


\subsection{The climatic contrast issue}

The aim of a DSST is to evaluate the robustness of a model under contrasted climate, an issue that is raised by CC applications for which one has to assume that calibrations performed under actual climate hold for future conditions. Even if it would be appropriate to recreate a DSST contrast that is of similar magnitude than the one expected under CC (i.e. try to "match" the projected contrast during the selection process), it will still not be a direct evaluation of the model robustness under $\mathrm{CC}$, since it would strictly be based on contrasted portions of an observed (actual) time series. It is preferable to interpret the DSST as an indicator of the robustness. This is also why we explore all diagonals in Figure 2 and not just the expected direction of the climate projections.

Furthermore, large uncertainties persist in climate projections. Hence "matching" these projections does not make any sense unless one also matches their associated uncertainties. It means that it is not possible to try to assess the impact of CC without taking the associated uncertainties into account. In other words, it is not possible to argue that a model will be robust in the context of a CC study because it is robust under a DSST involving a climatic contrast of the same magnitude as the average CC forecasted one. Also, as stated before, $\mathrm{P}$ and $\mathrm{T}$ consist in rough representatives of a year's climate. Consequently, matching these variables anticipated evolutions does not guarantee that the CC will be matched, because the term "climate" encompasses variables, statistics, and interactions way more numerous and complex than the two climatic variables considered in this study. Finally, CC impacts on the land use and vegetation characteristics are unaccounted for in a DSST (Refsgaard and Knudsen 1996). 


\subsection{DSST protocol}

A global selection (same years' selection for all catchments) was conducted. To do so, the total $\mathrm{P}$ and average $\mathrm{T}$ of each hydrologic year were computed for a given catchment using all meteorological grid points located inside it. Hydrologic years span from the 15th of November of the previous year to the 14th of November of the current year, in order to include the snow accumulation and melting processes of the winter season. $\mathrm{P}$ and $\mathrm{T}$ values were finally averaged over all 36 catchments.

The DSST exploited the 30-year period from 1980 to 2009. Selection of the 5 most extreme years per climatic quadrant relied on the distance with the median intersection in Figure 2. From experience, it is acceptable to calibrate the selected model on 5-year time series. The selected hydrologic years, for each climatic quadrant, are identified in Table 1 and drawn in Figure 3. Note that a test was made by selecting these years independently for each of the three main hydrologic regions of Figure 1, but this led to the exact same final set of selected years.

The DSST climatic contrast of the study is evaluated by the following two indicators:

$$
\begin{aligned}
& C p=\frac{\max (P 1, P 2)-\min (P 1, P 2)}{\min (P 1, P 2)} * 100 \\
& C t=\text { Tmoy }_{2}-\text { Tmoy }_{1}
\end{aligned}
$$

where $\mathrm{P} 1$ and $\mathrm{P} 2$ are the mean $\mathrm{P}$ values, and $\mathrm{Tmoy}_{1}$ and $\mathrm{Tmoy}_{2}$ are the mean $\mathrm{T}$ values, of opposite quadrants. Subscripts 1 and 2 respectively refer to the destination and original quadrants of a DSST, where by "original" we designate the quadrant used in calibration. $C p$ stands for "Contrast in precipitation" and $C t$ for "Contrast in temperature". Results are given in 
Table 2 for Diagonal 2 in its normal direction (from Dry Cold to Humid Warm, see Figure 6, and as expected by CC projections, see below), for which the percentiles represent the variability among the 36 catchments.

For comparison, contrasts reported on the same geographical region by Logan et al. (2011) for 2050 range between +2 and $+4^{\circ} \mathrm{C}$. $\left(10^{\text {th }}\right.$ and $90^{\text {th }}$ percentiles) for temperature and between 0 and $+25 \%\left(10^{\text {th }}\right.$ and $90^{\text {th }}$ percentiles $)$ for precipitation. Hence, the contrasts constructed by the DSST built here are lower than the anticipated ones.

\subsection{Calibration details}

13 free parameters of the hydrologic model Hydrotel were calibrated with the SCE-UA algorithm (Shuffled Complex Evolution algorithm from the University of Arizona, see Duan et al., 1994). This algorithm has been extensively used in the context of the calibration of complex hydrologic models. It is able to handle a large number of free parameters and avoids being trapped in local bumps or pits in the objective function surface, among other abilities. Table 3 below presents the description and ranges of these parameters.

The local objective function is the mean squared error

$$
M S E=\frac{1}{n} \sum_{t=1}^{n}\left(Q_{o}-Q_{s}\right)^{2}
$$

between the simulated $Q_{s}$ and observed flows $Q_{o}$ where $n$ is the number of observations, while the global objective function $F O_{\text {Global }}$ applied to the 36 catchments is

$$
F O_{\text {Global }}=\sum_{i=1}^{36} 1-\frac{N S_{G}(i)}{N S_{L}(i)}
$$


where $\mathrm{NS}_{\mathrm{G}}(\mathrm{i})$ is the Nash-Sutcliffe coefficient (Nash and Sutcliffe 1970) of catchment $i$ and $\mathrm{NS}_{\mathrm{L}}(\mathrm{i})$ is the same coefficient but from the local calibration procedure:

$$
N S=1-\frac{M S E}{\frac{1}{n} \sum_{t=1}^{n}\left(Q_{o}-\overline{Q_{o}}\right)^{2}}
$$

During the global calibration procedure, the aim is thus to simultaneously match, for the 36 catchments, the performances obtained from the local calibration procedure.

\subsection{Evaluation}

The whole concept behind the $N S$ is that a reference model is used to standardize the MSE for facilitating comparison between watersheds of different sizes and climates. It is however well known that the NS standardization is not perfect in that respect (Krause 2005). It is thus unadvisable to calculate the difference between two NS values, unless they originate from the same time series and watershed, for example comparing different versions of a model. In DSST, one encourages contrast between the calibration and test series, precluding a direct comparison of the $N S$ values computed from these dissimilar climates. A way to circumvent this problem is to compare the calibration performance (say on DC) to the test performance (also on DC) exploiting the parameter set obtained for the opposite series (HW), since both NS would then be computed on the same times series (DC). This alternative evaluation was used in Figure 4. 
Such analysis is complemented with the relative errors

$$
R e=\frac{L_{S}-L_{o}}{L_{o}} * 100
$$

where $\mathrm{L}_{\mathrm{s}}$ and $\mathrm{L}_{\mathrm{o}}$ are indicator values taken from the simulated and observed flow time series, respectively, applied to the maximum daily flow, the minimum seven-day flow (i.e., the flow averaged over a 7-days sliding window), and the mean flow over the period considered. The values of the maximum and minimum seven-day flows were obtained by taking the mean of the 5 annual values of each 5-year calibration or validation period, as a proxy for the value corresponding to a two-year return period. Despite the Nash-Sutcliffe criteria is generally the main score used to calibrate and assess the quality of an hydrologic model (Moriasi et al. 2007), it is strongly recommended by the hydrologic community (see previous reference) to use other metrics that focus on various aspects of the simulated streamflows, in order to have a broad and detailed view of a simulation's performances.

Finally, the Nash-Sutcliffe efficiency coefficient and the relative error for the mean flow were calculated for each month of the calibration and validation (or test) periods, in order to investigate a scheme's performances as a function of the period of the year considered.

\section{4-Results}

The local calibration strategy logically leads to better performances than the global one, both for calibration and test. This can be seen when looking at any of the criteria used in this study (Figures 4, 5 and 6), following Ricard et al. (2013) findings under SST. There is thus a performance cost to the advantages of a global calibration strategy, which allows preserving 
some spatial consistency for the parameter values and simulating ungauged catchments. For an example of spatial consistency of global calibration compared to local calibration ranges, see Figure 10. The term "spatial consistency" is here used in opposition to the results of local calibration, which tend to produce parameter values with a very high degree of variability inside a same region.

To investigate the parameter temporal transferability for both calibration schemes, it was chosen to compare NS values obtained over a test period, to those obtained over the same period but when it was used to calibrate the model when performing the DSST along the same climatic diagonal but in the reverse direction (see Figure 6). In other words, NS values obtained in calibration over a climatic quadrant of Figure 6 are taken as reference, and NS values obtained for the same quadrant when in test (or validation) mode with parameters obtained from the diagonally opposite quadrant are compared to it. To do the comparison, we hence examine $N S$ in test minus $N S$ in calibration (see section 3.4) but over the same period. A negative result depicts the logical superiority of the calibration over the test. This procedure is repeated for each calibration scheme. Ultimately, the global calibration presented in Figure 4 has more robustness than the local one (i.e., less performance difference between calibration and test periods), probably because the latter focuses on finding specialized parameters. Overspecialized calibration parameter sets may compensate for errors in the model structure and/or observed data (Merz et al. 2011). However, this errors' magnitude or influence may not be the same over the test period and the parameter set which was (too) appropriate over calibration is often less appropriate for testing. The global calibration is, by nature, less subject to overspecialization since it trades off parameters over numerous catchments. The observed data 
errors are therefore less compensated for, probably because they differ from one catchment to the other. This confers global calibration an important advantage.

Other tests were performed to investigate the potential benefits of conducting global calibration schemes on smaller areas than the one of $388000 \mathrm{~km}^{2}$ used in this study. More precisely, a global calibration was independently performed for each of the three main catchments of the studied area (see Figure 1). This strategy is here referred to as a semi-global calibration. This investigation is based on the assumption that using a unique parameter set for such a wide geographical zone may not be optimal. This strategy was only tested in the conventional direction of the CC, i.e. diagonal 2 in Figure 2. A priori, it seems that a semi-global calibration is beneficial to the model robustness, while limiting its loss in performance when compared to local calibration. In Figure 7, NS values in calibration and validation are not directly comparable because they were obtained over periods with different climatic properties (see above).

No climatic period (among the four climatic quadrants of this study, see Figure 2) simultaneously led to better performance in calibration and temporal robustness for all the criteria considered here, when compared to the other climatic quadrants.

In agreement with Ricard et al. (2013), it was noticed that high flows are generally underestimated (Figure 5) and low flows overestimated (Figure 6). This difficulty encountered by Hydrotel to simulate extreme flows (even with the local calibrations) may be due to inadequate model structure, the low resolution of the implemented models, but also partly to the difficulty of measuring the high spatial rainfall variability which can occur during summer periods (the rain gauge density inside a catchment is sometimes low). 
Investigating the mean flows relative errors on a monthly basis, one can see that it is generally overestimated during summer (June - October) and underestimated during winter (November, March - May) Figure 8). This situation is consistent whatever the climatic diagonal, direction, or period.

Performance obtained over winter is generally better than for summer (not shown here). This may be due to the fact that winter processes are easier to simulate since they are mostly governed by temperature during snowmelt and by the soil water content depletion at the beginning of the winter season. Summer periods are characterized by more complex events, involving a higher rainfall spatial variability caused by convective events, which are less common during winter. However, high winter flows present strong underestimations, as well as summer periods.

Finally, a discussion follows concerning a tendency relative to the simulated flows' behavior when moving from calibration to tests. This tendency is linked to the climatic contrast of the DSST. Moreover, it seems to be predominantly governed by temperature. Indeed, the mean simulated flows tend to increase when moving from warm to cold periods (i.e. when calibrating on warm and testing on cold periods), and vice-versa. This can be seen for example on Figure 9, but also on Figure 8. Of course, when moving from a cold to a warm period, evaporation is expected to increase, leading to a decrease in runoff. But what is observed in this work, and displayed on Figures 8 and 9, is that it is the relative error between observed and simulated flows which presents a tendency associated to the climatic change involved with the DSST. To give an example by putting Figure 9 into words, if observed flows are generally underestimated by the model in calibration over a cold (humid) period, they will be even more 
during validation over a warm (dry) period, as illustrated by local calibration on Figure 9. Hence this is independent from the expected change related to the climatic properties of the periods.

Such a tendency was also observed by Vaze et al. (2010) and Seiller et al. (2012), but it is assumed here that it can sometimes be more governed by precipitation than by temperature, maybe depending on each climatic variable's involved contrast. Other studies identified an opposite behavior, namely that the simulated flows can conserve the dynamic with which they were trained (see for example Klemeš 1986, Xu 1999, Merz et al. 2011, Coron et al. 2012). In other words, in such cases the observed flows can be underestimated in validation when training on dry (and/or warm) periods (and hence testing on humid and/or cold periods), and overestimated in validation when calibrating in runoff-favored situations like humid and/or cold periods.

It is hard to explain the reasons for such phenomena because it requires to link the calibrated parameter values (and their interactions) to model structure and behavior under different climatic conditions (Vaze et al. 2010). No explanation could be found in literature. Moreover, when looking at the aforementioned studies, no strong correlation could be established between the flows' tendency and either the catchment size, location, climate, model type (semi-distributed or global lumped conceptual), or objective function involved.

In situations where the model overestimates flows during test, when trained on a humid and/or cold period (and vice-versa), it seems that it tries to generate more runoff in order to simulate (i.e. mimic) the high flows of the calibration time series. In other cases like ours, for which the mean simulated flows decrease (possibly leading to underestimation) when moving 
from humid (and/or cold) to dry (and/or warm) periods, it seems that the model tries to take away water or at least to decrease runoff (i.e., to "fight" the climatic conditions) during calibration.

This behavior may be due to the global water balance of the model: if it does not produce enough runoff compared to what should be produced with its given inputs, it will try to increase it (by modifying the way precipitation is partitioned between evaporation and runoff, for example), which will result in overestimating low flows when exploited over dry periods. Otherwise (like for our findings), if it produces too much runoff when compared to what should be expected, it will compensate the water balance excess. This happens here with global calibration, for which the thickness of the third soil layer and the PET compensation factor tend to increase (which both decrease runoff) when the calibration period is humid and/or cold, and vice-versa (not shown here), as was envisioned by Vaze et al. (2010). This parameter's behavior is depicted in Figure 10 that illustrates the thickness of the third soil layer. The overspecialization of the local parameter sets hides this behavior that, associated to the parameter interdependency, leads to equi-finality and hence to a high variability of the parameter values. No hypothesis was found as to why third layer thickness values (Figure 10) are generally higher with global than with local calibration, as no in-depth analysis was performed in this study about the calibrated parameter values as a function of the climatic period used for calibration.

Another argument in favor of the explanation given here consists in the more pronounced tendency along the climatic diagonal 1, which involves a higher climatic contrast than the second one. Indeed, climatic diagonal 1 involves combinations of $\mathrm{P}$ and $\mathrm{T}$ with both variables being either in favor or against the generation of runoff. 
To confirm the hypotheses formulated here in regard of the behavior of a model general water balance when submitted to a DSST, the following test is proposed. One should calibrate and evaluate the model over a relatively long period (let's say 10 years in calibration and 10 in validation) using a standard SST procedure and local calibration, and assess if the model has a tendency of under or over-underestimating the overall water balance (using a bias criteria). If such a tendency is highlighted for the model using the conventional SST, then the DSST could be performed to see if the general tendency of the model can be linked to one of the two types of behavior discussed above when in DSST. Of course, several models and sub-catchments should be used to strengthen the resulting conclusions. This was done here as it would imply recalibrating the model using a conventional SST, whereas this paper focuses on DSST.

\section{5-Conclusion}

As was logically expected, local calibration leads, for a given gauged site, to better performance than global calibration, from the view point of all studied criteria and whatever the climatic diagonal or direction considered. However, local calibration is not devoid of drawbacks. Parameter sets can be over-specialized and lacking spatial (Bàrdossy 2007) or temporal transferability. Global calibration, however, allows preserving a spatial consistency of the parameter set and avoiding over-specialization, which can result in a better temporal robustness than local calibration. The semi-global strategy, which consists in performing the global calibration over a limited area, may even perform better than global calibration, depending on the degree of the spatial heterogeneities of the total area considered. 
It is here stated that a global calibration of the semi-distributed Hydrologic model Hydrotel over the large area of $388000 \mathrm{~km}^{2}$ studied here (south of Québec province) seems a promising direction in order to issue hydrologic projections. Indeed, the lower performances associated to using global instead of local calibration is tempered by the fact that the hydrologic projections (i.e., projections of climate change impacts on hydrologic regimes) mainly focus on evolution tendencies rather than on the absolute projected flow values themselves. In other words, even if global calibration predicts simulated flow values with a larger error than local calibration, it can predict correct flow tendencies that, in conjunction with its advantages, seem to make global calibration an appropriate tool for climate change impact studies over very large areas.

The Hydrotel model however may need improvements, especially regarding the simulation of extreme flow values. Using another objective function than simply the mean squared error during calibration, or increasing the model spatial resolution and the observation network density could also help reducing these drawbacks. 


\section{6-Acknowledgments}

We hereby acknowledge the Centre d'Expertise Hydrique du Québec (CEHQ) for the data, hydrologic model, Matlab functions, and financial support.

\section{7-References}

Andersen, J., Refsgaard, J., and Jensen, K. 2001. Distributed hydrological modelling of the Senegal River Basin--model construction and validation. J. Hydrol., 247: 200-214.

Bárdossy, A. 2007. Calibration of hydrological model parameters for ungauged catchments. Hydrology Earth Syst. Sci., 11: 703-710.

Beven, K., and Freer, J. 2001. Equifinality, data assimilation, and uncertainty estimation in mechanistic modelling of complex environmental systems using the GLUE methodology. J. Hydrol., 249: 11-29.

Centre d'expertise hydrique du Québec (CEHQ). 2012a. Mise en place d'une plateforme de modélisation hydrologique à l'échelle du Québec méridional. Québec, Québec. 25 pp. and appendices.

Centre d'expertise hydrique du Québec (CEHQ). 2012b. Production d'un atlas préliminaire des changements anticipés du régime hydrique du Québec méridional à l'horizon 2050. Québec, Québec. 55 pp. and appendices. 
Coron, L., Andréassian, V., Perrin, C., Lerat, J., Vaze, J., Bourqui, M., and Hendrickx, F. 2012. Crash testing hydrological models in contrasted climate conditions: an experiment on 216 Australian catchments. Water Resources Research, 48, W05552. doi:10.1029/2011WR011721, 2012

Bejarano, M.D., Marchamalo, M., de Jalon, D.G., del Tanago, M.G. 2010. Flow regime patterns and their controlling factors in the Ebro basin (Spain). J. Hydrol., 385: 323-335.

Duan, Q., Sorooshian, S., and Gupta, V. 1994. Optimal use of the SCE-UA global optimization method for calibrating watershed models. J. Hydrol., 158: 265-284.

Fortier Filion, T.C. 2011. Développement d'une procédure de mise en place d'un modèle hydrologique global sur des bassins jaugés et non jaugés : application du modèle MOHYSE au Québec. MSc. thesis, INRS-ETE, Québec, Canada.

Fortin, J., Turcotte, R., Massicotte, S., Moussa, R., Fitzback, J., and Villeneuve, J. 2001 a. Distributed watershed model compatible with remote sensing and GIS data. I: Description of model. J. Hydrol. Eng., 6(2): 91-99.

Fortin, J., Turcotte, R., Massicotte, S., Moussa, R., Fitzback, J., and Villeneuve, J. 2001b. Distributed watershed model compatible with remote sensing and GIS data. II: Application to Chaudière watershed. J. Hydrol. Eng., 6(2): 100-108.

Gotzinger, J., and Bárdossy, A. 2007. Comparison of four regionalisation methods for a distributed hydrological model. J. Hydrol., 333: 374-384. 
Klemeš, V. 1986. Operational testing of hydrological simulation models. Hydrolog. Sci. J., 31(1): 13-24.

Krause, P., Boyle, D.P., and Bäse, F. 2005. Comparison of different efficiency criteria for hydrological model assessment. Advances in Geosciences, 5: 89-97.

Logan, T., Charron, I., Chaumont, D., and Houle, D. 2011. Atlas de scénarios climatiques pour la forêt québécoise. Ouranos et MRNF. 55 pp. and appendices.

Mauser, W., and Bach, H. 2009. PROMET-Large scale distributed hydrological modelling to study the impact of climate change on the water flows of mountain watersheds. J. Hydrol., 376: 362377.

Merz, R., Parajka, J., and Blöschl, G. 2011. Time stability of catchment model parameters: Implications for climate impact analyses. Water Resour. Res., 47(1-17).

Nash, J.E., and Sutcliffe, J.V. 1970. River flow forecasting through conceptual models part I - A discussion of principles. Journal of Hydrology, 10 (3): 282-290.

Pietroniro, A., and Soulis, E. 2001. Comparison of global land-cover databases in the Mackenzie basin, Canada. Remote Sensing and Hydrology 2000 (Proceedings of a symposium held at Santa Fe, New Mexico, USA, April 2000). IAHS Publ. no. 267: 552-557.

Pietroniro, A., Fortin, V., Kouwen, N., Neal, C., Turcotte, R., Davison, B., Verseghy, D., Soulis, E., Caldwell, R., Evora, N., and others. 2007. Development of the MESH modelling system for 
hydrological ensemble forecasting of the Laurentian Great Lakes at the regional scale. Hydrology Earth Syst. Sci., 11: 1279-129.

Plummer, D.A., Caya, D., Frigon, A., Côté, H., Giguère, M., Paquin, D., Biner, S., Harvey, R., and De Elia, R. 2005. Climate and Climate Change over North America as Simulated by the Canadian RCM. Journal of Climate, 19: 3112-3132.

Ricard, S., Bourdillon, R., Roussel, D., and Turcotte, R. 2013. Global calibration of distributed hydrological models for large scale applications. Journal of Hydrologic Engineering, 18: 719-721.

Seiller, G., Anctil, F., and Perrin, C. 2012. Multimodel evaluation of twenty lumped hydrological models under contrasted climate conditions. Hydrol. Earth Syst. Sci., 16: 1171-1189.

Turcotte, R., Rousseau, A. N., Fortin J.-P., and Villeneuve. J.-P. 2003. Development of a processoriented, multiple-objective, hydrological calibration strategy accounting for model structure. Calibration of Watershed Models, Duan, Q., S. Sorooshian, H. Gupta, A. N. Rousseau et R. Turcotte, eds., Water Science and Application 6, American Geophysical Union, Washington, DC. 153-163.

Vaze, J., Post, D. A., Chiew, F. H. S., Perraud, J.-M., Viney, N. R., and Teng, J. 2010. Climate nonstationarity - Validity of calibrated rainfall-runoff models for use in climate change studies. J. Hydrol., 394: 447-457.

Xu, C.-Y. 1999. Operational testing of a water balance model for predicting climate change impacts. Agr. Forest Meteorol., 98-99: 295-304. 
Xu, C.-Y., Wid'en, E., and Halldin, S. 2005. Modelling hydrological consequences of climate change - progress and challenges. Adv. Atmos. Sci., 22: 789-797. 


\section{List of Tables:}

Table 1: Selected hydrological years for each climatic quadrant

Table 2: DSST climatic contrast along diagonal 2 (Figure 6) for the 36 catchments

Table 3: Description and ranges of the free parameters used to calibrate the model; PET:

Potential Evapo-Transpiration. See CEHQ (2012a) for the work originally proposing these ranges.

Table 1: Selected hydrological years for each climatic quadrant

\begin{tabular}{cccc}
\hline DW & HC & HW & DC \\
\hline 1998 & 1990 & 2006 & 1992 \\
1999 & 1996 & 2008 & 1982 \\
2002 & 1986 & 1983 & 1989 \\
2007 & 1993 & 2005 & 1985 \\
1987 & 1994 & 2000 & 2003 \\
\hline
\end{tabular}

Table 2: DSST climatic contrast along diagonal 2 (Figure 6) for the 36 catchments

\begin{tabular}{ccc}
\hline Percentiles $(\%)$ & $\mathrm{T}\left({ }^{\circ} \mathrm{C}\right)$ & $\mathrm{P}(\%)$ \\
\hline 25 & 1.40 & 10 \\
50 & 1.55 & 14 \\
75 & 1.70 & 20 \\
\hline
\end{tabular}


Table 3: Description and ranges of the free parameters used to calibrate the model; PET: Potential Evapo-Transpiration. See CEHQ (2012a) for the work originally proposing these ranges.

\begin{tabular}{|c|c|c|c|c|}
\hline parameter description / range & unit & initial & $\begin{array}{l}\text { lower } \\
\text { bound }\end{array}$ & $\begin{array}{l}\text { upper } \\
\text { bound }\end{array}$ \\
\hline PET multiplicative coefficient & [] & 0.7 & 0.7 & 1.5 \\
\hline $\begin{array}{l}\text { Ratio between evergreen and } \\
\text { deciduous trees snowmelt factors }\end{array}$ & [] & 1 & 0.5 & 1 \\
\hline deciduous trees snowmelt factor & [] & 6.4 & 1 & 20 \\
\hline $\begin{array}{l}\text { Ratio between bare ground and } \\
\text { deciduous trees snowmelt factors }\end{array}$ & [] & 1 & 1 & 2 \\
\hline $\begin{array}{l}\text { Difference between evergreen and } \\
\text { deciduous trees snowmelt threshlods }\end{array}$ & ${ }^{\circ} \mathrm{C}$. & 2.2 & 0 & 5 \\
\hline Deciduous tree snowmelt threshold & ${ }^{\circ} \mathrm{C}$. & 1,6 & -3 & 3 \\
\hline $\begin{array}{l}\text { Difference between bare ground and } \\
\text { deciduous trees snowmelt threshold }\end{array}$ & ${ }^{\circ} \mathrm{C}$. & -2.2 & -5 & 0 \\
\hline Depth of first soil layer & $\mathrm{m}$ & 0.1327 & 0.01 & 0.2 \\
\hline Second soil layer thickness & $\mathrm{m}$ & 0.4984 & 0.1 & 0.5 \\
\hline Third soil layer thickness & $\mathrm{m}$ & 0.5 & 0.5 & 2 \\
\hline recession coeff logarithm & [] & -10 & -10 & -1 \\
\hline Rain-snow temperature boundary & ${ }^{\circ} \mathrm{C}$. & 0 & -5 & 5 \\
\hline $\begin{array}{l}\text { Hydro-geomorphologic hydrogram } \\
\text { reference depth }\end{array}$ & $\mathrm{m}$ & 0.006 & 0.0015 & 0.025 \\
\hline
\end{tabular}




\section{List of Figures:}

Figure 1: The local (36 natural catchments), semi-global, and global scales of the experiment. A natural catchment is unregulated.

Figure 2: Definition of the four climatic quadrants, the two climatic diagonals, and the default directions used in the DSSTs. The dashed lines correspond to the median precipitation and temperature values for the period considered.

Figure 3: Selected hydrological years for each contrasted climate. Black squares represent the median of each climatic quadrant.

Figure 4: Nash values in test over a climatic period (i.e., simulations performed with parameters obtained from the diagonally opposite climatic quadrant), minus the Nash values obtained in calibration over the same period (see section 3.4). See Figure 2 for the explanation of the four climatic periods. Box-plots present the 5, 25, median, 75 and 90 percentiles over the 36 catchments. The blue line depicts the limit above which performances are generally judged as "satisfactory" in Hydrology. (a) and (b) panels: Global calibration along diagonals 1 and 2, respectively; (c) and (d) panels: local calibration along diagonals 1 and 2, respectively.

Figure 5: Relative errors of the maximum daily flows in calibration, for the four climatic periods. The ideal "no-error" value of 0 is displayed by a dashed grey line. Box-plots present the 5, 25, median, 75 and 90 percentiles over the 36 catchments.

Figure 6: Relative errors of the minimum seven-day flows in calibration, for the four climatic periods. The ideal "no-error" value of 0 is displayed by a dashed grey line. Box-plots present the 5,25 , median, 75 and 90 percentiles over the 36 catchments.

Figure 7: Nash-Sutcliffe values (ideal value is 1 ) along climatic diagonal 2. Box-plots present the 5, 25, median, 75 and 90 percentiles over the 36 catchments. The blue line depicts the limit above which performances are generally judged as "satisfactory" in Hydrology.

Figure 8: Mean relative errors (along the 36 catchments used) of the mean monthly flows, using climatic diagonal 1.

Figure 9: Interannual hydrographs (i.e., simulated flows averaged over a set of 5 years) computed using climatic diagonal 1 (Calibration over Humid Cold and validation with Dry Warm climate) and station 041902 (Dumoine river, outlet of lake Robinson), located at the outlet of a $3760 \mathrm{~km}^{2}$ catchment in the Ottawa River basin (second most western catchment of Figure 1).

Figure 10: Calibrated third soil layer thickness; box-plots depict the variability over the 36 catchments in local calibration and the black dots represent the global calibration values. 


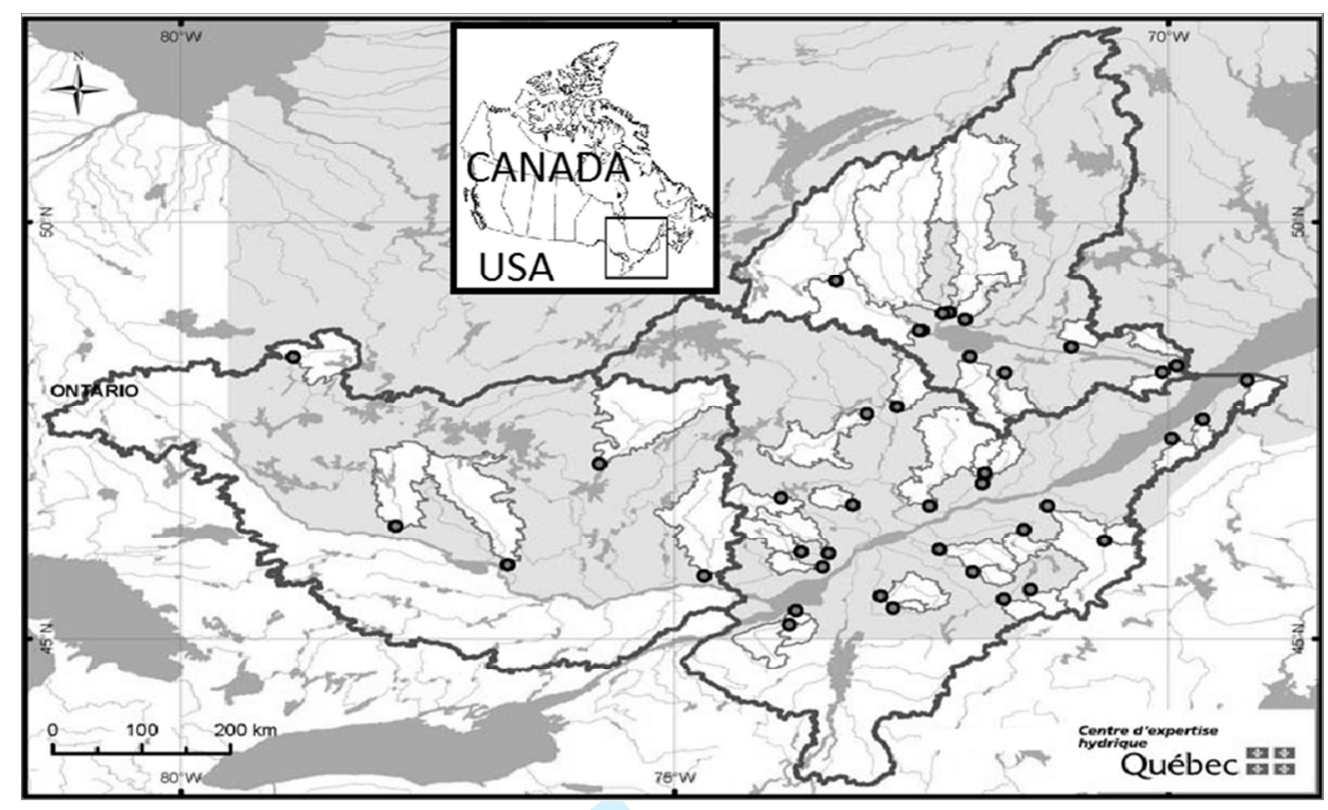




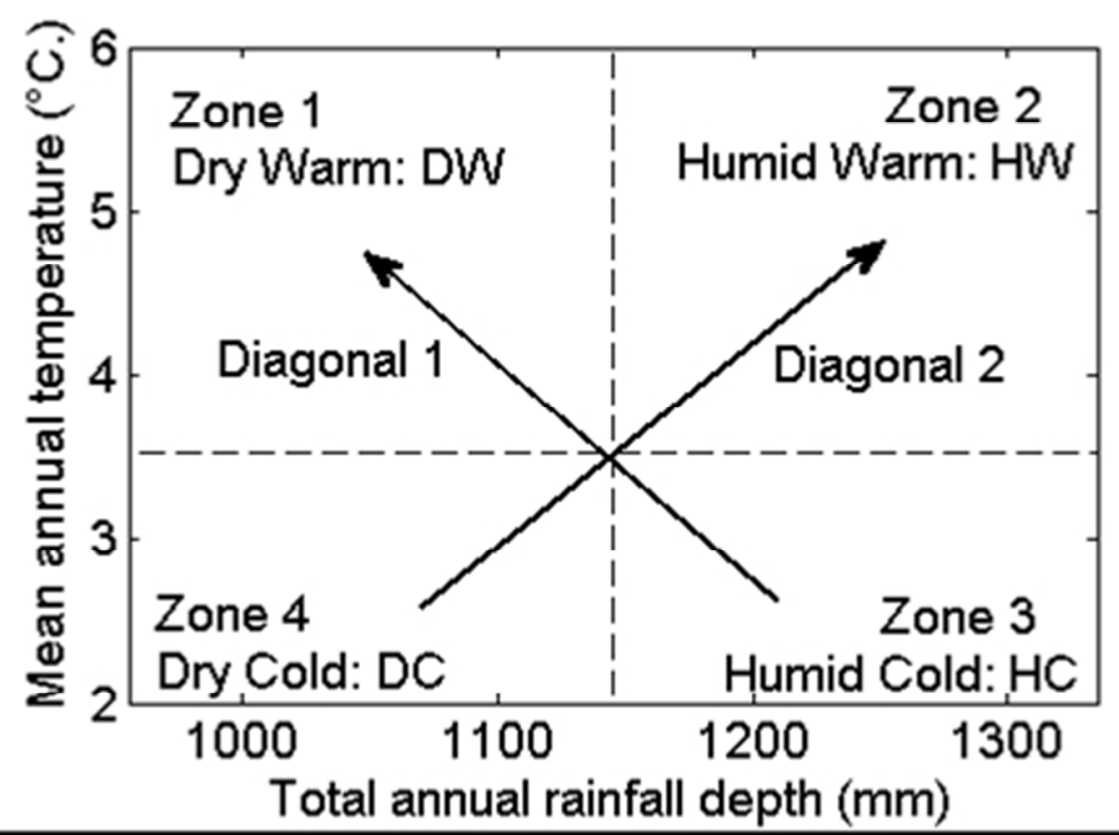




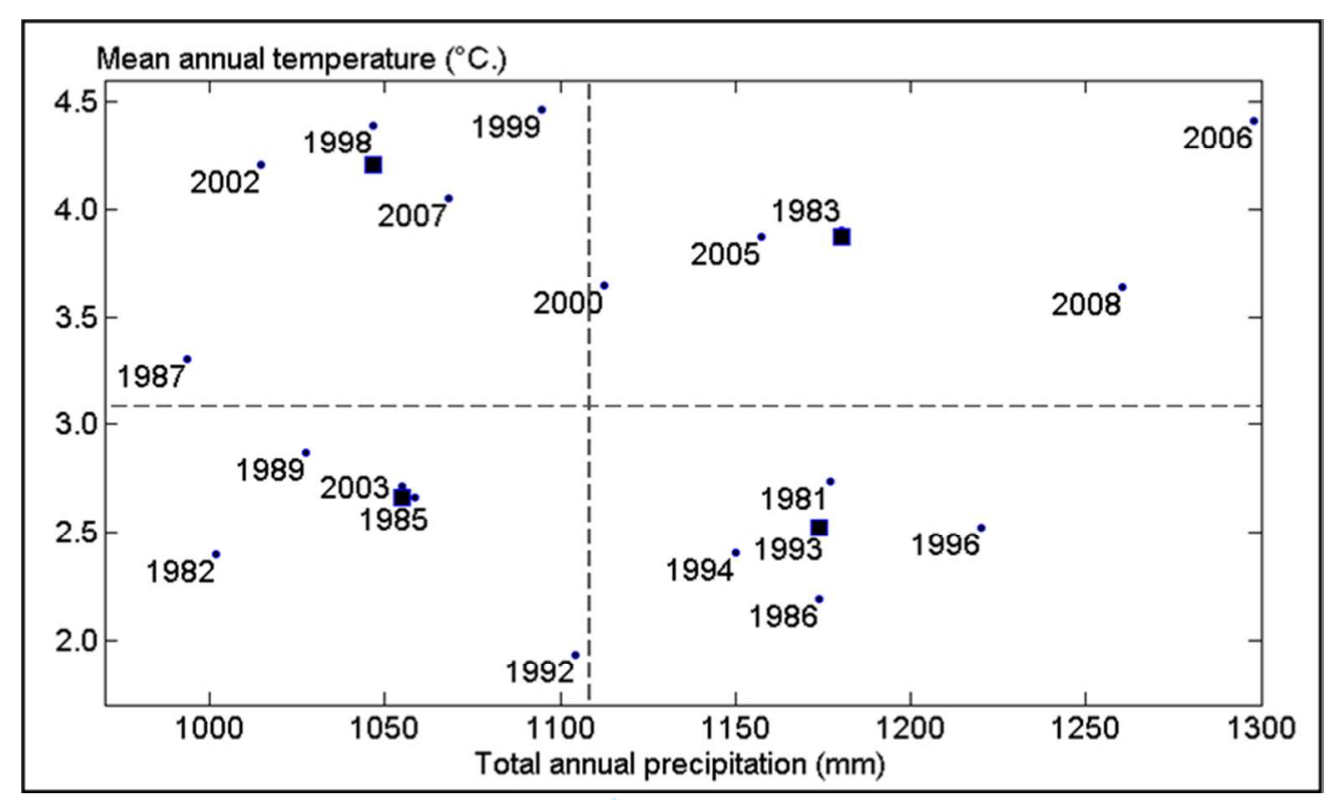

https://mc06.manuscriptcentral.com/cjes-pubs 


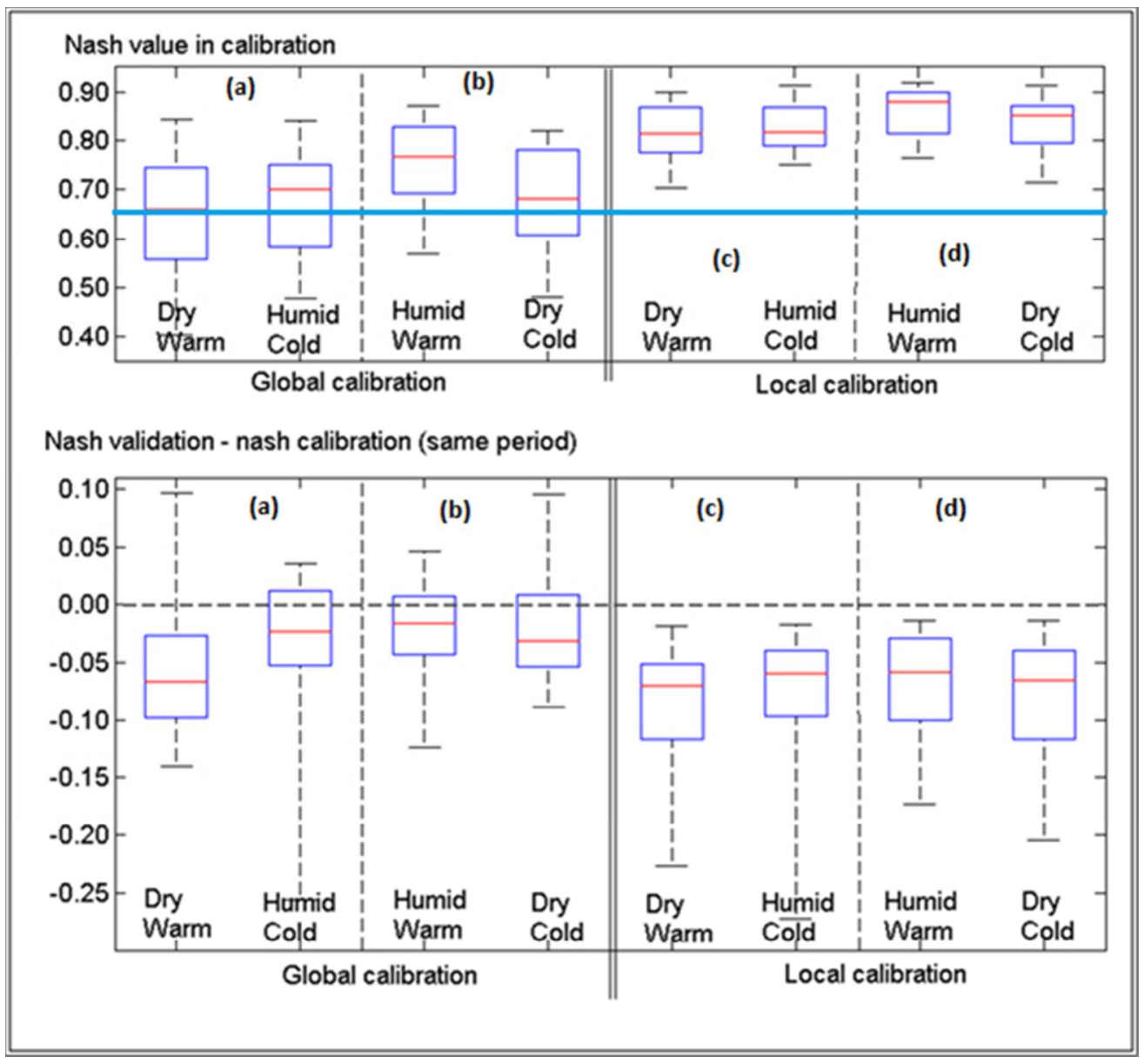




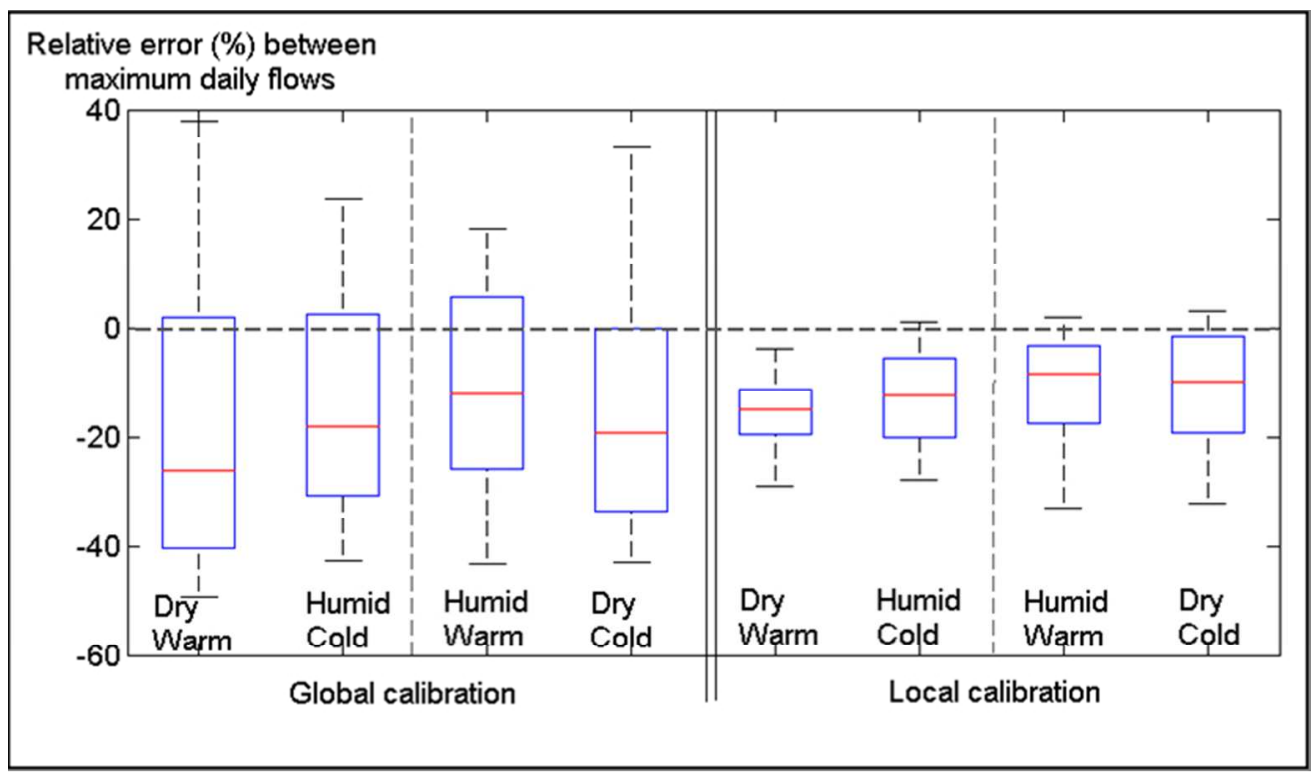




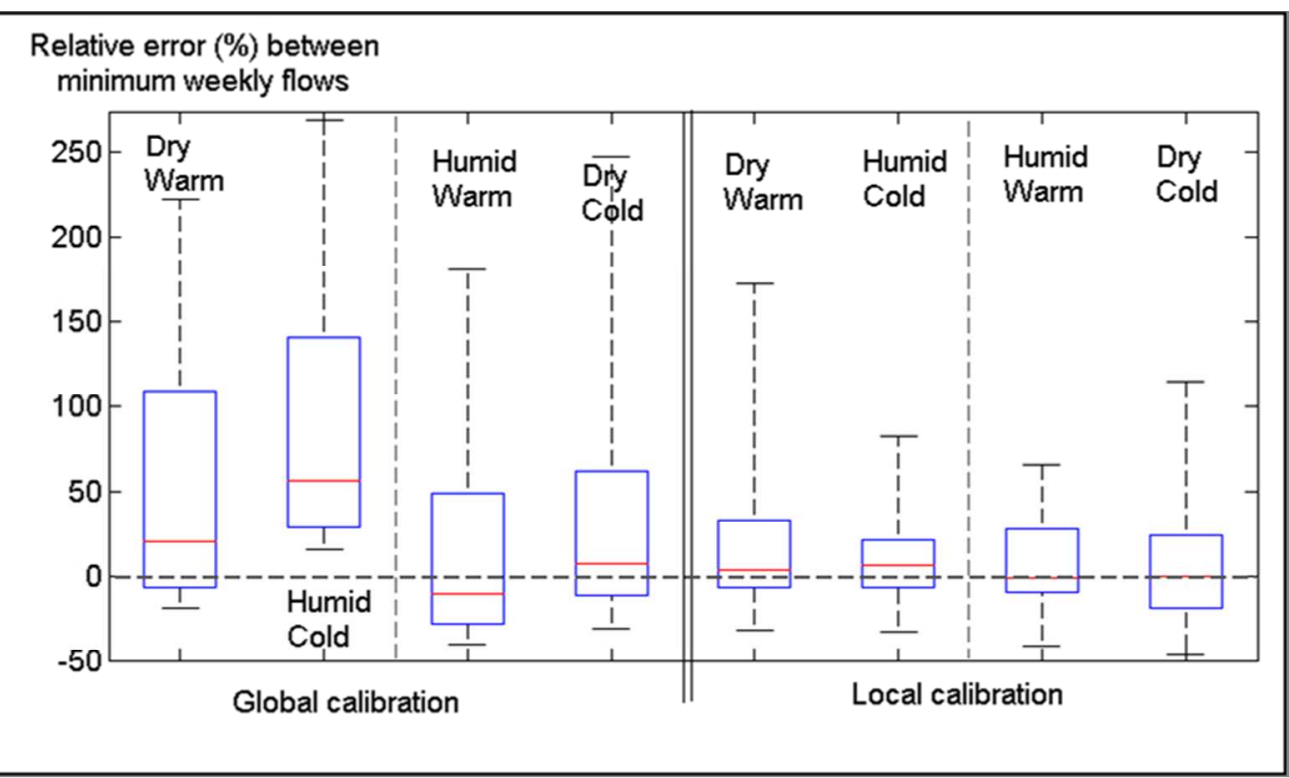




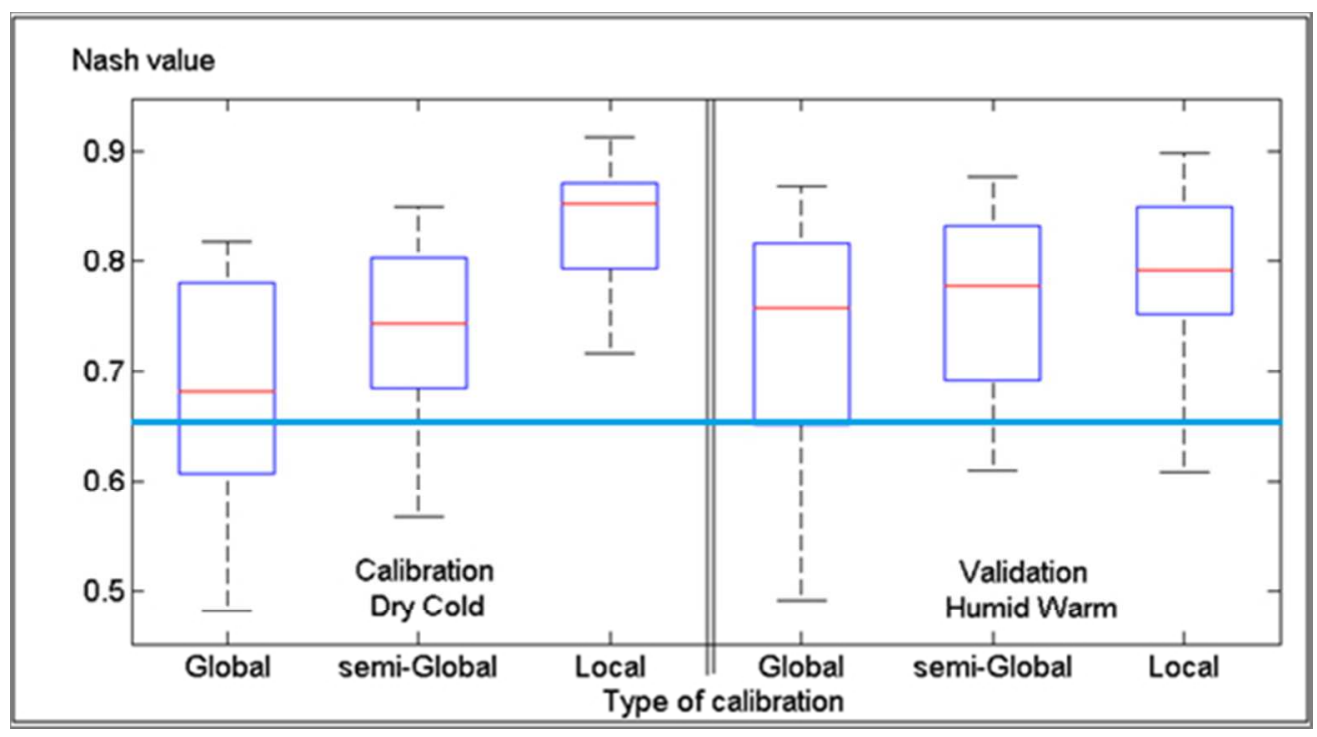

https://mc06.manuscriptcentral.com/cjes-pubs 


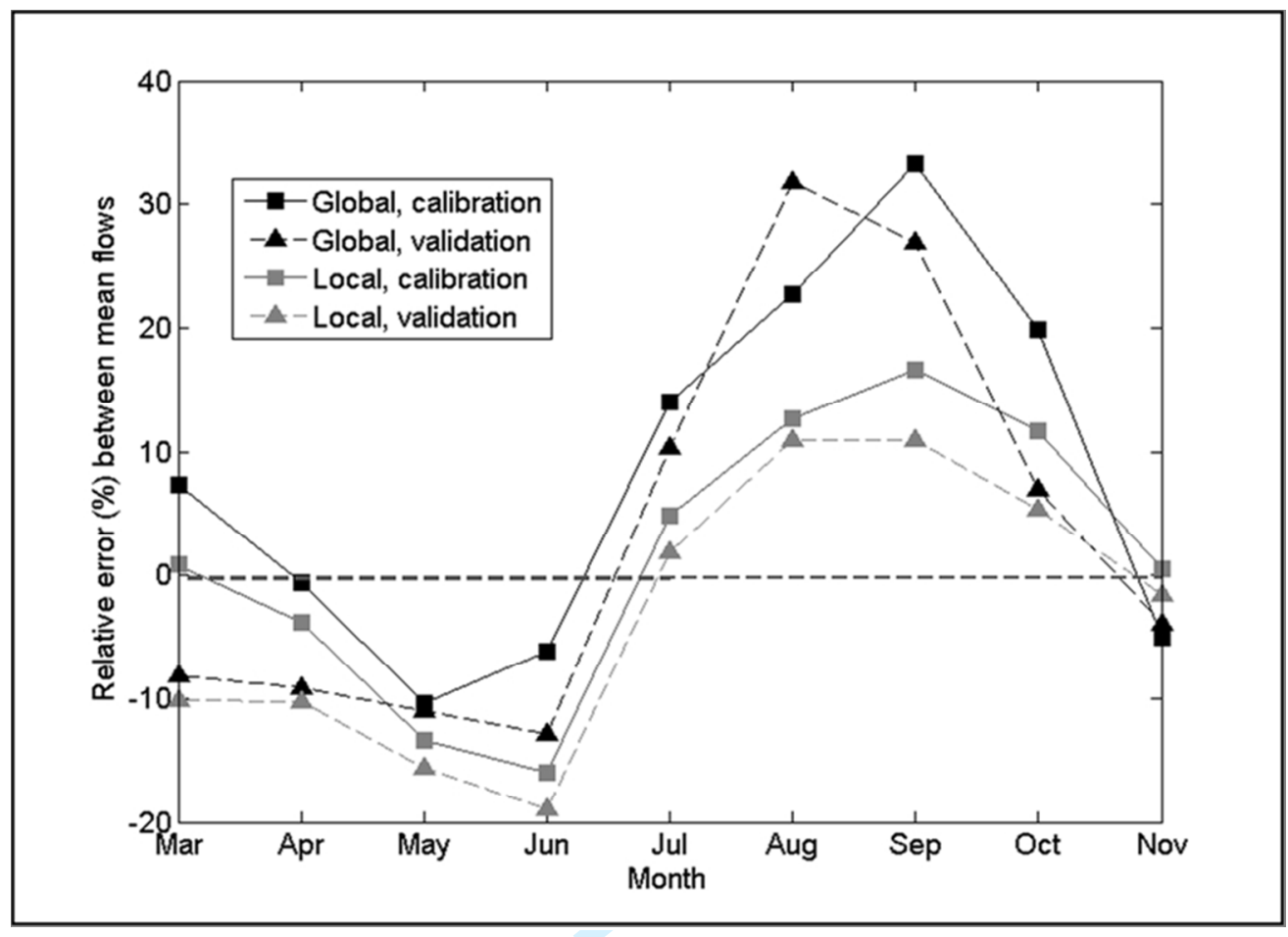




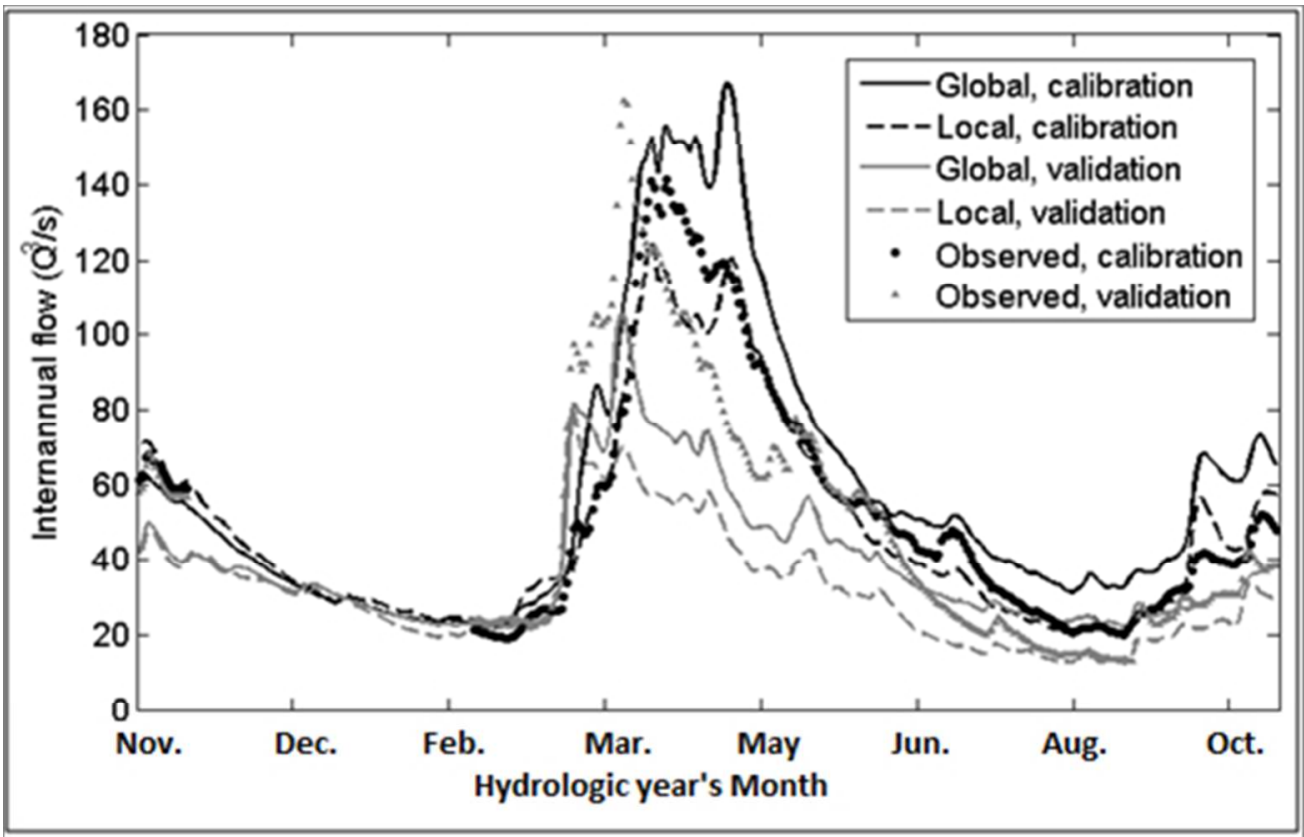




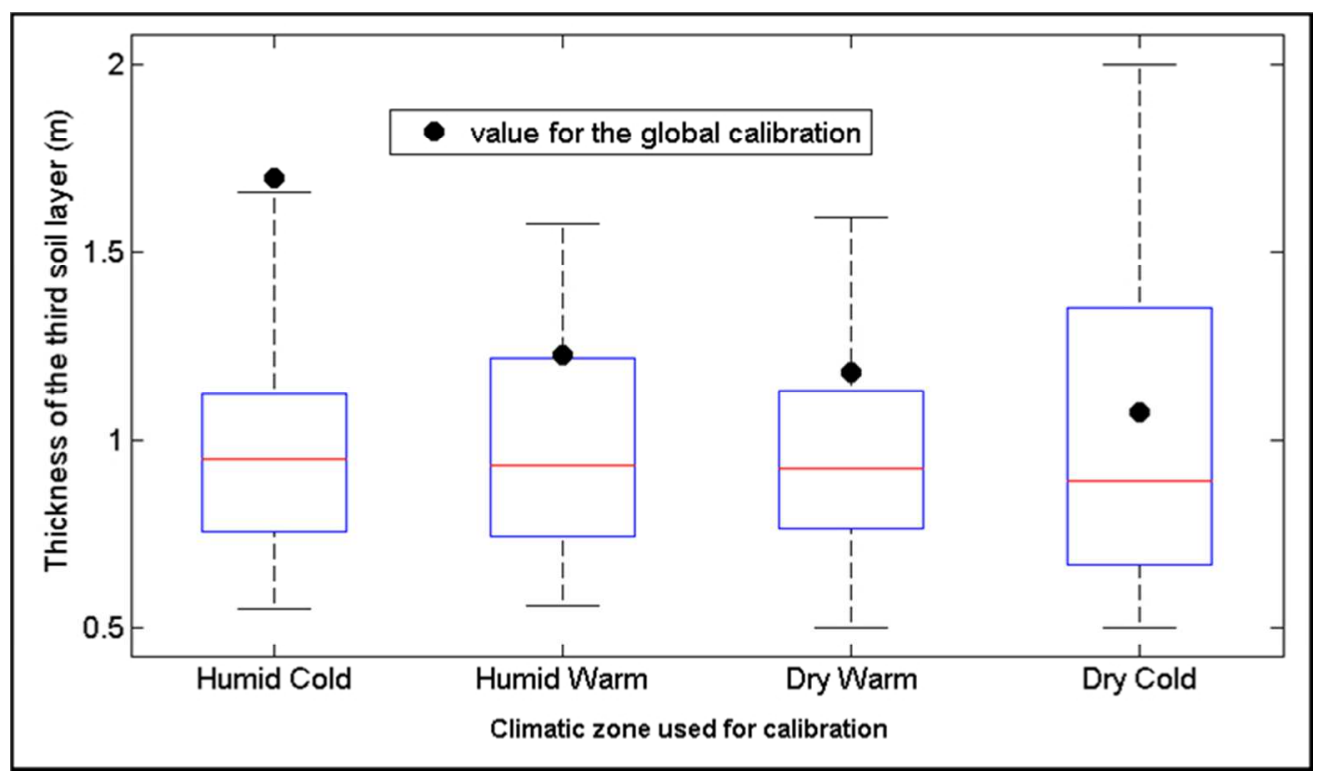

